\title{
Launching a New Journal in Times of COVID
}

\author{
Hans Zappe \\ Editor-in-Chief
}

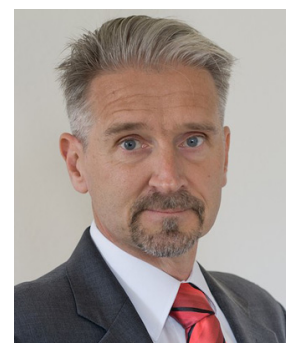

In Gabriel García Márquez's great novel Love in the Time of Cholera, it takes decades amongst the vicissitudes of a cholera epidemic for the two main characters to find happiness together. In the more prosaic climes of scientific publishing, will the Journal of Optical Microsystems find happy authors and readers, after being launched during one of the most devastating pandemics in modern memory? After our first year, our hopes are high!

By the end of 2021, JOM has published 25 manuscripts, including four review papers, and now includes an international spectrum of highly regarded researchers working in the optical microsystems field amongst its authors. We are grateful to all of them for taking the risk and diving into a new, unknown and completely unproven journal as a venue for publication of their most exciting research results.

Of course, nothing will make our authors happier than having their work read and cited, and with more than 27,000 paper downloads so far in 2021, we are confident that JOM has quite solidly appeared on the optics publishing scene. More and more readers are navigating to the journal website, numbers which will certainly grow rapidly as the catalogue of published manuscripts continues to expand. Coupling happy authors with happy readers: that seems to have succeeded in our first year.

But it hasn't been a cakewalk, far from it. Some of us, yours truly included, imagined that the wide-ranging restrictions placed on researchers due to various levels of lockdowns, from not being able to go to the lab to not being able to go anywhere, would give everyone more time to finally write all those papers in the queue. Well, that perception soon proved to be a touch naive. Being locked out of the lab doesn't yield much more time when we have to reconfigure all our classes to be taught remotely or organize endless Zoom meetings to keep our research groups running, all the while home-schooling our kids. No, there are not too many silver linings to a pandemic.

All the more reason for me personally to be grateful not only to the teams of JOM authors that did come through with manuscripts but also to our extremely hardworking editorial board who tracked down and convinced those teams to publish with us. Our board has now grown to a group of 23 experts in the varied areas of optical microsystems, and it is through their tireless efforts that JOM has made it through its first year in the best of health. All the senior and associate editors can also be happy with the fruits of their labors.

As we now enter our second year, with few signs that the COVID pandemic will be abating anytime soon, we of course have plenty of challenges ahead: we're just off the starting line, but the race is a long one. With the unwavering support of our editorial team, the entire SPIE publications team, our authors, and not least you, our readers, we have every reason to believe that the Journal of Optical Microsystems can generate some professional and scientific happiness in these somewhat bleak times.

\footnotetext{
(C) The Authors. Published by SPIE under a Creative Commons Attribution 4.0 International License. Distribution or reproduction of this
} work in whole or in part requires full attribution of the original publication, including its DOI. 